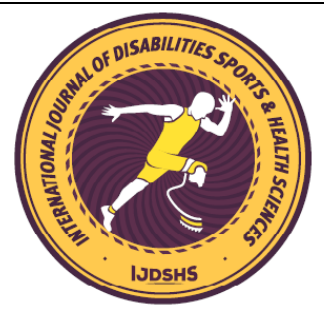

\title{
Effects of Diaphragmatic Mobilization and Diaphragmatic Breathing Exercises on Pain and Quality of Life in Individuals with Shoulder Pain: A Randomized Controlled Trial
}

\author{
Okan ŞAHIN ${ }^{* 1}$ and Deniz KOCAMAZ
}

${ }^{1}$ Istanbul Health and Technology University, Faculty of Health Sciences, Department of Physical Therapy and Rehabilitation, Istanbul, Turkey

${ }^{2}$ Hasan Kalyoncu University, Faculty of Health Sciences, Department of Physical Therapy and Rehabilitation, Gaziantep, Turkey

*Corresponding author: okan.sahin@istun.edu.tr

\begin{abstract}
Purpose: This study aimed to investigate the effects of diaphragmatic mobilization and diaphragmatic breathing exercises on pain and quality of life in individuals with shoulder pain. Methods: A total of 72 individuals with shoulder pain were included in the study. The individuals included in the study were randomly divided into 3 groups as Diaphragmatic Mobilization Group (DMG) $(n=24)$, Diaphragmatic Breathing Group (DBG) $(n=24)$, and control group $(n=24)$. In addition to classical physiotherapy treatment, diaphragmatic mobilization to mobilization group and diaphragmatic breathing exercises to breathing group were applied by the physiotherapist 3 days a week for 8 weeks. On the other hand, only classical physiotherapy treatments were applied to the control group. Individuals were evaluated in terms of pain and quality of life. Pain levels assessed with the Visual Analogue Scale (VAS) and quality of life assessed with Short Form-36 (SF-36). Results: In our study, it was observed that the pain level was reduced and the quality of life was improved in all groups $(\mathrm{p}<0.05)$. When DMG and DBG were compared with the control group, there was found a significant difference among groups in terms of reducing pain and improving quality of life in favor of DMG and DBG $(\mathrm{p}<0.05)$. When DMG and DBG were compared, no statistically significant difference was found between the groups $(p>0.05)$. Conclusion: The study results demonstrated that diaphragmatic mobilization and diaphragmatic breathing exercises are found to be effective in reducing pain and improving quality of life in individuals with shoulder pain.
\end{abstract}

Keywords

Diaphragmatic Mobilization, Breathing Exercises, Shoulder pain, Quality of life

\section{INTRODUCTION}

Shoulder pain is a common musculoskeletal problem that significantly affects the general population. The prevalence of shoulder pain is between $6 \%$ and $26 \%$ worldwide. It is thought that one out of every three people will experience shoulder pain at least once in their lifetime. The most common clinical types of shoulder pain are rotator cuff lesions, adhesive capsulitis, and glenohumeral osteoarthritis (Struyf et all., 2016; Oliveira et all., 2017).

The shoulder pain is a health problem that is not limited to personal factors but also affects the physical and psychosocial working environment of the individual. It significantly affects the quality of life of the individual (Ariëns et all., 2001). It is one of the important public health problems that can have major medical and economic consequences 
on individuals, communities and industries and it may restrict productivity in workplaces (Sundstrup and Andersen, 2017; Murray et all., 2013).

In individuals with shoulder pain, it is very important to distinguish the source of the pain, considering that the shoulder pain originating from the glenohumeral joint usually might be compensated by the scapulothoracic joint (Magee, 2008).

In case of increased strength and stress; If biomechanical connections such as optimal muscle flexibility, muscle strength, proprioception, and endurance can not be established, it may cause pain and injury in the shoulder joint (Sciascia and Cromwell 2012; Karandikar and Vargas 2011).

The factors that cause shoulder pain are not always clear. It can be caused by different complex reasons that, the shoulder pain does not always consist of dysfunction of structures such as muscles or joints. It should be considered if there is a musculoskeletal disorder existed or not, only it should be taken into account also the common shoulder pain which is experienced after stroke. (Langhorne, 2000). On the other hand, shoulder pain and dysfunction can also be caused by pathological conditions in the spine, rib cage or internal organs. It is known that pain from dysfunctions anywhere in the spine or rib cage can accelerate shoulder dysfunction. For this reason, the relationships between the rib and the shoulder, which are important in respiration, should not be ignored (Donatelli, 2012).

Shoulder pain can lead to decreased normal joint range of motion, sleep disorders, anxiety and anxiety disorder in individuals (Neviaser and Hannafin 2010; Ryan et all., 2016).

In individuals with shoulder pain, deep breathing exercises and relaxation exercises are considered to improve daily life activities by reducing the pain of the patient (Friesner et all., 2006; Schaffer and Yucha, 2004).

It has been mentioned in many studies that breathing exercises significantly affect the physical and mental state of the individual. These studies have revealed that diaphragm training has an effect on the body's organs and musculoskeletal system. Eliminating the symptoms of gastroesophageal reflux and improving lumbosacral muscle proprioception are typical examples of these findings (Nobre et all., 2013).

Diaphragm activity affects respiratory capacity and generally changes the perception of pain in individuals. In addition, by providing deep breathing and increasing the diaphragm efficiency, a healthy posture and body position are maintained (Bordoni and Marelli, 2016; Bordoni et all., 2016).

In the literature, there are studies that report on the effects of breathing exercises on pain, function, and balance. (Lee, 2015; Stephens et all., 2017). However, there is no study in the literatüre that investigate the effectiveness of the diaphragmatic mobilization and diaphragmatic breathing exercise on shoulder pain and quality of life in individuals with shoulder pain.

The aim of this study was to investigate the effects of diaphragmatic mobilization and diaphragmatic breathing exercises on shoulder pain and quality of life in individuals with shoulder pain. The study hypothesis was that the diaphragmatic mobilization and diaphragmatic breathing exercises applied in addition to classical physiotherapy treatment would have a greater effect than solo classical physiotherapy treatment on decreasing shoulder pain and improving the quality of life.

\section{MATERIALS AND METHODS}

The study was conducted on individuals with shoulder pain in Gaziantep Büyükşehir Belediyesi Inayet Topcuoglu Hospital. Approval for this randomized controlled trial was granted by the Human Research Ethics Committee of Hasan Kalyoncu University (date-decision no: 19/01/2021-2021/008). All study procedures conformed to the provisions of the World Medical Association Declaration of Helsinki. Written informed consent was obtained from all participants. Our study was carried out between 20 January - 30 May 2021. The individuals included in our study were randomized by drawing lots.

\section{Participants}

A total of 72 individuals with shoulder pain, aged between 18-64 were included in the study. The participants were divided into three groups according to the simple random method as the 1st control group (n:24), the 2nd mobilization group (n:24) and the 3rd breathing group (n:24).

The inclusion criteria of our study were shoulder patients diagnosed by a physician between the ages of 18-65 and individuals with pain in active shoulder flexion and abduction or with normal range of motion limitation. 
The exclusion criteria of our study; individuals who smoked, have muscle strength below 4, have neurological pathology, have cardiological problems, have shoulder surgery, have shoulder dislocation or subluxation, have thoracic surgery, have a respiratory disorder, were diagnosed with mental health problems and did not accept to volunteer.

\section{Measurements}

At the start of the study, the demographic information of all the subjects in all groups was recorded, then Visual Analogue Scale (VAS) and Short Form-36 (SF-36) were recorded. In addition, pulse and oxygen saturation were evaluated by pulse oximetry. At the end of training sessions completed in a 8-week period, all the evaluations and scales were applied again.

\section{The Visual Analog Scale (VAS)}

This scale was used to evaluate the pain. According to the VAS, pain severity is graded as "no pain" as 0 points and "worst pain imaginable" as 10 points (10 cm scale) (Hawker et al., 2011). VAS is a reliable and valid pain measurement method in the evaluation of pain (Kurşun et al., 2015).

\section{The Short Form-36 Health Survey (SF-36)}

The Short Form-36, which is frequently used to assess the quality of life, provides a wide-angle measurement. The scale consists of eight subscales including physical function, physical role, emotional function, social function, general health, mental health, pain, and vitality. Each subscale scores between 0-100 and the scale is directly proportional to the quality of life. 100 points reflect the best health status, while 0 pounds indicate the worst health status. The Turkish validity and reliability study of the quality of life questionnaire which is Short Form-36 (SF-36) conducted (Koçyiğit et al., 1999).

\section{The Pulse Oximetry}

Pulse oximetry is a device that noninvasively measures oxygen saturation by recording the light absorption of different hemoglobins in arteries with a beating heart (Kuzu et al., 2017). It is a painless and reliable tool (Khan et al., 2017). Finger type pulse oximeter device was used to measure oxygen saturation and pulse.

\section{Intervention}

Only classical physiotherapy treatments were applied to individuals in the control group. In addition to classical physiotherapy treatment, diaphragmatic mobilization to mobilization group and diaphragmatic breathing exercises to breathing group were applied by the physiotherapist 3 days a week for 8 weeks. Classical physiotherapy treatment includes Transcutaneous Electrical Nerve Stimulation (TENS) for 15 minutes, hotpack on the painful area for 15 minutes, and theraband exercises in the directions of shoulder flexion, abduction, external and internal rotation were prescribed as strengthening exercises.

Diaphragmatic mobilization was applied to the mobilization group by the physiotherapist while the participant was in a supine and relaxed position. Thumbs are placed on the xiphoid process. The costae are grasped and closed up together, with the remaining fingers together and the fingertips reaching into the lumbar region and drawing a virtual 8 motion. The diaphragmatic mobilization was applied in each session for 3 minutes (Fig.1).

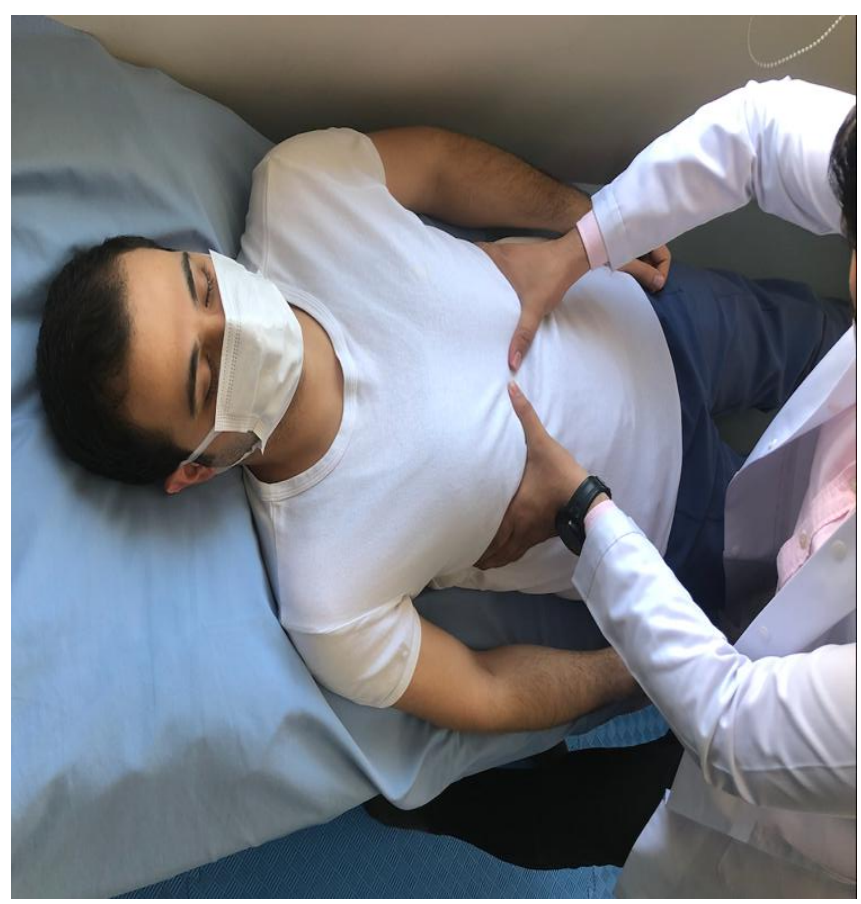

Figure 1. Diaphragmatic mobilization

Diaphragmatic breathing exercise is performed as the patient placing one hand on the chest and the other hand on the abdomen while the individual is in the supine position, with minimal chest movement, breathing slowly and deeply through the nose for 4 seconds and exhaling through the mouth for 6 seconds approximately. The patient is instructed not to move the hand on the chest and pushing the air to the abdomen causing the hand there to move (Fig.2). 


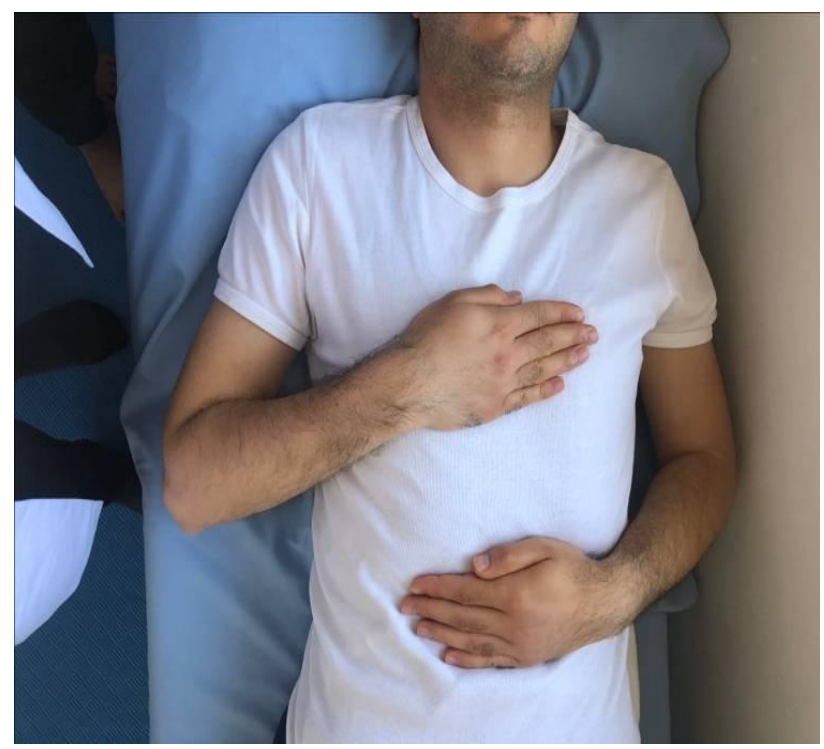

Figure 2. Diaphragmatic breathing exercise

\section{Statistical Analysis}

Data obtained in the study were analyzed statistically using IBM SPSS vn. 21.0 software (SPSS Inc, Chicago, IL, USA). As the data did not conform to a normal distribution, non-parametric tests were used in the analyses. In the comparisons of the mean values of three independent groups, the Mann-Whitney $U$ test was used. The mean values within a group of the measurements taken before and after the exercise training were evaluated using the Wilcoxon Signed-Rank test. In the determination of the differences between groups of categorical variables, the Chi-square test was applied. In all the data analyses, a value of $\mathrm{p}<0.05$ was accepted as statistically significant.

\section{RESULTS}

A total of 72 individuals with shoulder pain, 59 female (\%82) and 13 male (\%18), aged between 18-64, were included in the study. It was observed that the control group (age: $41.67 \pm 12.06$ years, body mass index: $\left.26.08 \pm 2.81 \mathrm{~kg} / \mathrm{m}^{2}\right)$ mobilization group (age: 36.62 \pm 9.09 years, body mass index: $26.275 \pm 4.03 \mathrm{~kg} / \mathrm{m}^{2}$ ) and respiratory group (age: $39.5 \pm 7.08$ years, body mass index: $27.77 \pm 3.69 \mathrm{~kg} / \mathrm{m}^{2}$ ) were similar in terms of age and body mass index. Demographic characteristics of individuals such as gender, occupational group, diagnosis, respiratory type, chest type, and dominant side were recorded. The demographic features of the all groups are shown in Table 1.

Table 1. Demographic features

\begin{tabular}{|c|c|c|c|c|c|c|c|}
\hline & & \multicolumn{2}{|c|}{$\begin{array}{l}\text { Control } \\
\text { group } \\
(n=24)\end{array}$} & \multicolumn{2}{|c|}{$\begin{array}{c}\text { Mobilization } \\
\text { group } \\
(n=24)\end{array}$} & \multicolumn{2}{|c|}{$\begin{array}{l}\text { Breathing } \\
\text { group } \\
(n=24)\end{array}$} \\
\hline & & $\mathbf{n}$ & $\%$ & $\mathbf{n}$ & $\%$ & $\mathbf{n}$ & $\%$ \\
\hline \multirow[t]{2}{*}{ Gender } & Male & 21 & 87.5 & 16 & 66.7 & 22 & 91.7 \\
\hline & Female & 3 & 12.5 & 8 & 33.3 & 2 & 8.3 \\
\hline \multirow{6}{*}{ Profession } & Office worker & 1 & 4.2 & 2 & 8.3 & 2 & 8.3 \\
\hline & Housewife & 15 & 62.5 & 12 & 50 & 16 & 66.7 \\
\hline & Student & 2 & 8.3 & 2 & 8.3 & - & - \\
\hline & Worker & 1 & 4.2 & 5 & 20.8 & 4 & 16.7 \\
\hline & Retired & 3 & 12.5 & 2 & 8.3 & 1 & 4.2 \\
\hline & Unemployed & 2 & 8.3 & 1 & 4.2 & 1 & 4.2 \\
\hline \multirow{4}{*}{ Diagnosis } & Adhesive capsulite & 4 & 16.7 & 3 & 12.5 & 2 & 8.3 \\
\hline & Impingement & 4 & 16.7 & 1 & 4.2 & 3 & 12.5 \\
\hline & Rotator cuff lesion & 8 & 33.3 & 16 & 66.7 & 13 & 54.2 \\
\hline & Tenosynovitis & 8 & 33.3 & 4 & 16.7 & 6 & 25 \\
\hline \multirow[t]{3}{*}{ Respiratory type } & Chest breathing & 15 & 62.5 & 16 & 66.7 & 15 & 62.5 \\
\hline & Diaphragm breathing & 7 & 29.2 & 7 & 29.2 & 5 & 20.8 \\
\hline & Mix & 2 & 8.3 & 1 & 4.2 & 4 & 16.7 \\
\hline \multirow[t]{3}{*}{ Chest type } & Normal & 18 & 75 & 16 & 66.7 & 22 & 91.7 \\
\hline & Pigeon chest & 4 & 16.7 & 5 & 20.8 & 2 & 8.3 \\
\hline & Barrel chest & 2 & 8.3 & 3 & 12.5 & - & - \\
\hline \multirow[t]{2}{*}{ Dominant side } & Right & 20 & 83.3 & 23 & 95.8 & 23 & 95.8 \\
\hline & Left & 4 & 16.7 & 1 & 4.2 & 1 & 4.2 \\
\hline
\end{tabular}


When the pain severity and respiratory values of the groups were compared before and after the treatment, a statistically significant decrease in pain was found in all three groups $(\mathrm{p}<0.05)$. When peripheral oxygen saturation values were examined, there was a statistically significant increase in DMG and DSG ( $\mathrm{p}<0.05)$. There was no significant difference in pulse values before and after the treatment $(\mathrm{p}>0.05)$. When the quality of life sub-parameters of the groups were evaluated before and after the treatment, an improvement in the quality of life was observed in all groups $(\mathrm{p}<0.05)$. Comparison of pain, respiratory parameters and quality of life of the groups before and after the treatment are shown in Table2.

Table 2. Comparison of Pain, Respiratory Parameters and Quality of Life of The Groups Before And After The Treatment

\begin{tabular}{lcccccc}
\hline \multirow{1}{*}{ Measurements } & \multicolumn{2}{c}{$\begin{array}{c}\text { Control } \\
\text { group } \\
(n=24)\end{array}$} & $\begin{array}{c}\text { Mobilization } \\
\text { group } \\
(n=24)\end{array}$ & \multicolumn{2}{c}{$\begin{array}{c}\text { Breathing } \\
\text { group } \\
(n=24)\end{array}$} \\
\cline { 2 - 7 } & $\mathbf{z}$ & $\mathbf{p}$ & $\mathbf{z}$ & $\mathbf{p}$ & $\mathbf{z}$ & $\mathbf{p}$ \\
\hline Pain Activity & -4.301 & 0.000 & -4.304 & 0.000 & -4.315 & 0.000 \\
Pain Rest & -4.306 & 0.000 & -4.300 & 0.000 & -4.331 & 0.000 \\
Pain Sleep & -4.222 & 0.000 & -4.296 & 0.000 & -4.212 & 0.000 \\
SpO2 & -1.393 & 0.164 & -1.966 & 0.049 & -2.847 & 0.004 \\
Pulse & -0.053 & 0.958 & -0.660 & 0.509 & -0.815 & 0.415 \\
Physical Functioning & -4.222 & 0.000 & -4.298 & 0.000 & -4.296 & 0.000 \\
Physical Role Functioning & -4.406 & 0.000 & -4.418 & 0.000 & -4.365 & 0.000 \\
Emotional Role Functioning & -4.036 & 0.000 & -4.244 & 0.000 & -4.358 & 0.000 \\
Vitality(energy) & -3.358 & 0.001 & -4.035 & 0.000 & -3.937 & 0.000 \\
Mental Health & -3.127 & 0.002 & -4.265 & 0.000 & -4.213 & 0.000 \\
Social Function & -4.164 & 0.000 & -4.303 & 0.000 & -4.334 & 0.000 \\
Pain & -4.205 & 0.000 & -4.203 & 0.000 & -4.296 & 0.000 \\
General Health & -3.826 & 0.000 & -4.302 & 0.000 & -4.232 & 0.000 \\
\hline
\end{tabular}

*p<0.05 Wilcoxon Signed Ranks Test, SpO2; Peripheral Oxygen saturation

When the pain severity among the groups were examined, it was found that there was a significant decrease in pain activity, pain resting and pain sleep parameters after treatment $(\mathrm{p}<0.05)$. There was no difference in the comparison of peripheral oxygen saturation values between the groups before and after the treatment $(p>0.05)$. When the pulse values among the groups were examined, a statistically significant increase was found in the pulse values after the treatment $(\mathrm{p}<0.05)$. The intergroup comparison of pain and respiratory parameters is shown in Table 3 .
As a result of the comparison of the quality of life sub-parameters among the groups, an improvement in the quality of life was observed in the parameters of emotional role difficulty, mental health, pain, and general health perception $(p<0.05)$. In the energy parameter, there was an improvement in the values before and after the treatment $(\mathrm{p}<0.05)$. No statistically significant difference was found in all other parameters $(p>0.05)$. The intergroups comparison of quality of life are shown in Table 4. 
Table 3. The Intergroups comparison of pain and respiration parameters

\begin{tabular}{|c|c|c|c|c|c|c|}
\hline & \multirow{2}{*}{ Measurements } & $\begin{array}{c}\text { Controlgroup } \\
(n=24)\end{array}$ & $\begin{array}{c}\text { Mobilization group } \\
(n=24)\end{array}$ & $\begin{array}{l}\text { Breathing group } \\
\quad(n=24)\end{array}$ & & \\
\hline & & $\mathrm{X} \pm \mathrm{SD}$ & $\mathbf{X} \pm \mathbf{S D}$ & $\mathbf{X} \pm \mathbf{S D}$ & $X^{2}$ & $\mathbf{p}$ \\
\hline \multirow{2}{*}{$\begin{array}{l}\text { Pain } \\
\text { Activity }\end{array}$} & Before Treatment & $8.54 \pm 1.22$ & $8.63 \pm 1.10$ & $8.75 \pm 1.36$ & 0.717 & 0.699 \\
\hline & After Treatment & $3.46 \pm 2.13$ & $1.79 \pm 1.69$ & $1.5 \pm 1.62$ & 12.845 & 0.002 \\
\hline \multirow{2}{*}{ Pain Rest } & Before Treatment & $6.88 \pm 1.60$ & $7.63 \pm 1.93$ & $6.67 \pm 1.93$ & 3.568 & 0.168 \\
\hline & After Treatment & $2.42 \pm 1.93$ & $0.83 \pm 1.34$ & $1.04 \pm 1.20$ & 11.332 & 0.003 \\
\hline \multirow[t]{2}{*}{ Pain Sleep } & $\mathrm{p}$ Before Treatment & $6.96 \pm 2.51$ & $7.63 \pm 2.24$ & $7.83 \pm 2.60$ & 3.210 & 0.201 \\
\hline & After Treatment & $2.04 \pm 1.94$ & $0.83 \pm 1.44$ & $0.88 \pm 1.26$ & 8.430 & 0.015 \\
\hline \multirow{2}{*}{$\mathrm{SpO} 2$} & Before Treatment & $96.46 \pm 1.98$ & $96.88 \pm 1.68$ & $96.04 \pm 2.31$ & 1.632 & 0.442 \\
\hline & After Treatment & $96.83 \pm 1.63$ & $97.42 \pm 1.25$ & $97.25 \pm 1.33$ & 1.666 & 0.435 \\
\hline \multirow[t]{2}{*}{ Pulse } & Before Treatment & $78.67 \pm 6.64$ & $79.42 \pm 10.73$ & $83.96 \pm 9.59$ & 5.324 & 0.070 \\
\hline & After Treatment & $78.5 \pm 6.64$ & $80.04 \pm 8.81$ & $82.88 \pm 6.04$ & 7.242 & 0.027 \\
\hline
\end{tabular}

Table 4. The Intergroups comparison of quality of life

\begin{tabular}{|c|c|c|c|c|c|c|}
\hline \multirow{2}{*}{\multicolumn{2}{|c|}{ SF-36 Sub-Parameters }} & \multirow{3}{*}{$\begin{array}{c}\begin{array}{c}\text { Control group } \\
(n=24)\end{array} \\
\mathbf{X} \pm \mathbf{S D} \\
59.17 \pm 22.10\end{array}$} & \multirow{3}{*}{$\begin{array}{c}\begin{array}{c}\text { Mobilization group } \\
(n=24)\end{array} \\
\mathbf{X} \pm \mathbf{S D} \\
53.33 \pm 16.40\end{array}$} & \multicolumn{3}{|c|}{$\begin{array}{c}\text { Breathing group } \\
(n=24)\end{array}$} \\
\hline & & & & \multirow{2}{*}{$\begin{array}{c}\mathbf{X} \pm \mathbf{S D} \\
48.75 \pm 21.23\end{array}$} & \multirow{2}{*}{$\frac{\mathbf{X}^{\mathbf{2}}}{3.797}$} & \multirow{2}{*}{$\begin{array}{l}\mathbf{p} \\
0.150\end{array}$} \\
\hline Physical & Before Treatment & & & & & \\
\hline Functioning & After Treatment & $76.88 \pm 19.27$ & $83.75 \pm 10.14$ & $79.58 \pm 13.98$ & 1.326 & 0.515 \\
\hline Physical Role & Before Treatment & $31.25 \pm 26.84$ & $24.38 \pm 19.47$ & $16.88 \pm 17.68$ & 3.487 & 0.175 \\
\hline Functioning & After Treatment & $72.92 \pm 24.36$ & $73.13 \pm 17.99$ & $63.54 \pm 22.09$ & 2.639 & 0.267 \\
\hline Emotional Role & Before Treatment & $34.28 \pm 31.89$ & $14.04 \pm 16.99$ & $15.26 \pm 19.60$ & 5.834 & 0.054 \\
\hline Functioning & After Treatment & $83.35 \pm 19.64$ & $72.24 \pm 23.40$ & $63.90 \pm 16.80$ & 12.859 & 0.002 \\
\hline \multirow{2}{*}{ Vitality(energy) } & Before Treatment & $38.96 \pm 18.06$ & $45.62 \pm 17.71$ & $51.88 \pm 14.05$ & 6.452 & 0.040 \\
\hline & After Treatment & $47.71 \pm 15.88$ & $64.79 \pm 14.10$ & $68.75 \pm 14.98$ & 20.198 & 0.000 \\
\hline \multirow{2}{*}{ Mental Health } & Before Treatment & $43.33 \pm 19.69$ & $51.79 \pm 17.95$ & $52.67 \pm 13.08$ & 4.527 & 0.104 \\
\hline & After Treatment & $53.92 \pm 15.33$ & $65.88 \pm 11.78$ & $67.25 \pm 11.35$ & 12.296 & 0.002 \\
\hline \multirow{3}{*}{ Social Function } & Before Treatment & $44.77 \pm 20.83$ & $32.12 \pm 20.13$ & $36.45 \pm 14.71$ & 4.557 & 0.102 \\
\hline & After Treatment & $64.56 \pm 16.38$ & $67.15 \pm 10.86$ & $70.83 \pm 14.12$ & 2.302 & 0.316 \\
\hline & Before Treatment & $30.29 \pm 20.22$ & $23.12 \pm 15.43$ & $27.60 \pm 16.24$ & 1.571 & 0.456 \\
\hline Pain & After Treatment & $59.39 \pm 16.38$ & $78.54 \pm 18.19$ & $76.43 \pm 14.50$ & 15.003 & 0.001 \\
\hline \multirow{2}{*}{ General Health } & Before Treatment & $34.38 \pm 19.30$ & $39.17 \pm 24.83$ & $45.42 \pm 20.59$ & 2.572 & 0.276 \\
\hline & After Treatment & $45.62 \pm 19.07$ & $64.17 \pm 18.51$ & $61.46 \pm 16.45$ & 11.297 & 0.004 \\
\hline
\end{tabular}


In the pairwise comparison of the groups; improvements after the treatment in favor of DMG and DSG were noted in terms of pain activity, pain rest, and pain sleep parameters, as the quality of life sub-parameters of energy, mental health, pain, and general health perception $(\mathrm{p}<0.05)$. After the treatment, an improvement was observed in the quality of life in favor of DSG in terms of the quality of life emotional role difficulty parameter $(\mathrm{p}<0.05)$. The pairwise comparison of groups are shown in table 5 .

Tablo 5. Pairwise comparison of groups

\begin{tabular}{lcccccc}
\hline & \multicolumn{2}{c}{ Control Mobilization } & \multicolumn{2}{c}{ Control Breathing } & \multicolumn{2}{c}{ Mobilization Breathing } \\
\cline { 2 - 7 } & $\mathrm{z}$ & $\mathrm{p}$ & $\mathrm{z}$ & $\mathrm{p}$ & $\mathrm{z}$ & $\mathrm{p}$ \\
\hline Pain Activity & $\mathbf{- 2 . 7 7 6}$ & $\mathbf{0 . 0 0 5}$ & $\mathbf{- 3 . 2 9 9}$ & $\mathbf{0 . 0 0 1}$ & -0.624 & 0.532 \\
Pain Rest & $\mathbf{- 3 . 0 3 8}$ & $\mathbf{0 . 0 0 2}$ & $\mathbf{- 2 . 5 6 8}$ & $\mathbf{0 . 0 1 0}$ & -0.767 & 0.443 \\
Pain Sleep & $\mathbf{- 2 . 5 4 8}$ & $\mathbf{0 . 0 1 1}$ & $\mathbf{- 2 . 3 2 8}$ & $\mathbf{0 . 0 2 0}$ & -0.290 & 0.771 \\
Emotional Role Functioning & -1.898 & -1.898 & $\mathbf{- 3 . 5 2 5}$ & $\mathbf{0 . 0 0 0}$ & -1.767 & 0.077 \\
Vitality (energy) & $\mathbf{- 3 . 6 2 4}$ & $\mathbf{0 . 0 0 0}$ & $\mathbf{- 3 . 9 9 4}$ & $\mathbf{0 . 0 0 0}$ & -1.142 & 0.253 \\
Mental Health & $\mathbf{- 2 . 9 9 2}$ & $\mathbf{0 . 0 0 3}$ & $\mathbf{- 3 . 0 3 1}$ & $\mathbf{0 . 0 0 2}$ & -0.549 & 0.583 \\
Pain & $\mathbf{- 3 . 3 8 0}$ & $\mathbf{0 . 0 0 1}$ & $\mathbf{- 3 . 2 7 6}$ & $\mathbf{0 . 0 0 1}$ & -0.532 & 0.594 \\
General Health & $\mathbf{- 3 . 0 3 4}$ & $\mathbf{0 . 0 0 2}$ & $\mathbf{- 2 . 6 7 4}$ & $\mathbf{0 . 0 0 7}$ & -0.698 & 0.485 \\
\hline
\end{tabular}

*p<0.05 Mann-Whitney U Test,

\section{DISCUSSION}

The aim of this study was to investigate the effects of diaphragmatic mobilization and diaphragmatic breathing exercises on shoulder pain and quality of life in individuals with shoulder pain. Diaphragm mobilization and diaphragmatic breathing exercises, which are applied in addition to classical physiotherapy treatment are found to be effective in reducing pain and improving the quality of life in individuals with shoulder pain. Therefore, we think that the diaphragm mobilization technique and diaphragmatic breathing exercises should be a part of shoulder rehabilitation in the literature with their role in reducing pain perception and improving the quality of life. A pilot study was conducted with 27 people diagnosed with rotator cuff injury and its findings have not been shared yet. In this study, 3 groups consisting of 9 people in each group were formed. Myofascial trigger point treatment was applied to the control group, manual therapy to the diaphragm group, and diaphragm mobilization with respiratory exercise to the respiratory group. (Fernández-López et all., 2021). We think that the sample we created with
72 individuals as a result of the power analysis and literature study is more comprehensive than the studies in the literature.

In the literature, the effect of breathing exercises on pain, shoulder joint range of motion and balance has been investigated (Lee, 2015; Stephens et all., 2017). The originality of our study is that it is the first study to examine the effects of diaphragmatic mobilization and diaphragmatic breathing exercises on pain and quality of life in individuals with shoulder pain.

There is no study in the literature that reveals the effects of diaphragmatic mobilization and diaphragmatic breathing exercises on pain and quality of life in individuals with shoulder pain. The findings of a study investigated the effect of deep breathing exercise training applied with Proprioceptive Neuromuscular Facilitation (PNF) exercises on shoulder normal range of motion and pain in a female case. The 46-year-old patient underwent resistance exercise in the upper extremity flexion, abduction and external rotation pattern. In addition, deep breathing exercises were applied for 3 weeks, 3 sessions per week for 30 minutes. As a result of the research, an increase in 
the patient's normal range of motion and a decrease in pain was found (Lee, 2015).

In our study, pain assessment was performed with VAS. When the groups were compared before and after the treatment, a significant difference was found in the reduction of pain level in all three groups. As a result of the pairwise comparison of the groups, when the VAS values of the diaphragmatic mobilization and diaphragmatic breathing exercise groups were compared to the control group, it was statistically revealed that there was a greater decrease in pain level. VAS is a reliable and valid pain measurement method in the evaluation of pain (Kurşun et all., 2015). We think that diaphragmatic mobilization and diaphragmatic breathing exercises applied in the treatment of individuals with shoulder pain reduce sleep problems, increase the treatment motivation of individuals and reduce the perception of pain.

Shoulder pain is considered a multifactorial health problem that is not only limited to individual factors but also related to both the physical and psychosocial work environment (Ariëns et all., 2001). As it causes pain and disability in individuals with rotator cuff lesions, which is one of the most common causes of shoulder pain, it affects performance in activities of daily living. Shoulder pain significantly affects the quality of life of individuals (Osborne et all., 2016). In individuals with shoulder pain, deep breathing exercises and relaxation exercises are considered to improve the daily life of the patient by reducing the pain (Friesner et all., 2006; Schaffer and Yucha, 2004).

When the pre-treatment and post-treatment SF-36 parameters of all groups included in our study were evaluated, it was determined that the quality of life increased in all groups. When the quality of life was examined among the groups, a significant difference was found in the improvement in the sub-parameters of SF-36 emotional role difficulty, energy, mental health, pain and general health perception. In the pairwise comparison of the groups, SF-36 energy, mental health, pain, and general health perception parameters improved in favor of DMG and DSG compared to the control group. In our study, it was observed that the exercise and mobilization practices we performed for DMG and DSG, to increase the efficiency of the diaphragm, which plays an important role in respiration, apart from the practices in the control group, improved the quality of life to a greater extent in favor of DMG and DSG.

The respiratory and autonomic nervous systems have a close relationship with each other. The phrenic nerve, which provides the innervation of the movement of the diaphragm muscle, is connected to the vagus (parasympathetic) nerve (Kocjan et all., 2017). Diaphragmatic breathing exercise activates parasympathetic nerve activity while suppressing sympathetic nerve activity (Ambrosino, et all., 1981). Chang et al. reported that 8 deep breaths per minute predominated the balance of parasympathetic nerve activity. (Chang et all., 2013). Jerath et al. They stated that breathing stimulates vagal activation of gammaaminobutyric acid pathways in the brain and reduces stress and anxiety. In addition, it is seen that diaphragmatic breathing exercise has a positive effect on the cardiovascular system and brain by improving autonomic balance (Jerath et all., 2015).

In our study, when the groups were compared, a significant improvement was observed in the SF-36 emotional role difficulty sub-parameter only in favor of the diaphragmatic respiratory group. We think that this significant improvement in favor of the only DSG is due to the positive effect of respiratory exercises on the mental health of the individual in terms of biopsychosocial.

During this period of the Covid-19 pandemic, our study contributed to the awareness of breathing exercises. Not only the mobilization and breathing exercise groups but also the control group were informed about effective and correct breathing.

There were some limitations to this study. While our study was being planned, it was considered to use a pulmonary function test in order to evaluate the diaphragm efficiency with more quantitative measurements. However, the prohibition of the use of pulmonary function tests in hospitals except in very emergency situations due to the Covid-19 pandemic caused the diaphragm efficiency to not be evaluated quantitatively enough.

Although our study was carried out with a large number of participants compared to the literature, one of the limitations of our study was that it was conducted in a single center. 
This study could not be carried out with a homogeneous gender distribution, since the participants were mostly female.

The fact that the education levels of the individuals participating in our study were mostly low, caused a great loss of time, especially in the evaluation part based on the questionnaire. In the literature, strong conclusions could not be made due to the few studies examining the shoulderdiaphragm relationship in patients with shoulder pain.

We think that our study, which we carried out in a single center and with individuals who are very similar in terms of sociodemographics, is carried out by multiple centers and groups of individuals from all parts of the society, may increase the reliability of future studies.

As a result, diaphragmatic mobilization and diaphragmatic breathing exercises were effective in reducing pain and improving the quality of life in individuals with shoulder pain. We think that increasing the activity of the diaphragm muscle via diaphragmatic mobilization and diaphragmatic breathing exercise plays a role in reducing shoulder pain because of a clear relationship between the diaphragm and the shoulder both in terms of anatomy and through myofascial connection. For this reason, we think that it would be beneficial to include diaphragmatic mobilization and diaphragmatic breathing exercises in addition to the classical physiotherapy program in the treatment protocols of individuals with shoulder pain.

\section{Conflicts of interest}

All authors have no conflicts of interest with respect to the data collected and procedures used within this study. Authors declare that they have no sponsor in the study design, collection, analysis, writing of the manuscript, and decision to submit the manuscript for publication.

\section{Ethics Statement}

The studies involving human participants were reviewed and approved by the Hasan Kalyoncu University, Non-Interventional Research Ethics Committee (Date: 19.01.2021; Decision / Protocol number: 2021/008). Written informed consent to participate in this study was provided by the patients/participants.

\section{REFERENCES}

Ambrosino, N., Paggiaro, P. L., Macchi, M., Filieri, M., Toma, G., Lombardi, F. A., Del Cesta, F., Parlanti, A., Loi, A. M., \& Baschieri, L. (1981). A study of short-term effect of rehabilitative therapy in chronic obstructive pulmonary disease. Respiration; international review of thoracic diseases, 41(1), 40-44.

Ariëns, G. A., van Mechelen, W., Bongers, P. M., Bouter, L. M., \& van der Wal, G. (2001). Psychosocial risk factors for neck pain: a systematic review. American journal of industrial medicine, 39(2),180193.

Bordoni, B., \& Marelli, F. (2016). Failed back surgery syndrome: review and new hypotheses. Journal of pain research, 9, 1722.

Bordoni, B., Marelli, F., \& Bordoni, G. (2016). A review of analgesic and emotive breathing: a multidisciplinary approach. Journal of multidisciplinary healthcare, 9, 97-102.

Chang, Q., Liu, R., \& Shen, Z. (2013). Effects of slow breathing rate on blood pressure and heart rate variabilities. International journal of cardiology, 169(1), e6-e8.

Donatelli R.A. (2012). Physical Therapy of the Shoulder. Fifth Edition. PhD, PT, OCS National Director of Sports Rehabilitation Physiotherapy Associates. Las Vegas, Nevada. ISBN: 978-1-4377-0740-3.

Fernández-López, I., Peña-Otero, D., AtínArratibel, M., Eguillor-Mutiloa, M., BravoLlatas, C., Genovés-Crespo, M., \& CallejasGonzález, F. J. (2021). Effects of diaphragm muscle treatment in shoulder pain and mobility in subjects with rotator cuff injuries: A dataset derived from a pilot clinical trial. Data in brief, 35, 106867.

Friesner, S. A., Curry, D. M., \& Moddeman, G. R. (2006). Comparison of two painmanagement strategies during chest tube removal: relaxation exercise with opioids and opioids alone. Heart \& lung: the journal of critical care, 35(4), 269-276.

Hawker, G. A., Mian, S., Kendzerska, T., \& French, M. (2011). Measures of adult pain: Visual Analog Scale for Pain (VAS Pain), Numeric Rating Scale for Pain (NRS Pain), McGill Pain Questionnaire (MPQ), ShortForm McGill Pain Questionnaire (SF-MPQ), 
Chronic Pain Grade Scale (CPGS), Short Form-36 Bodily Pain Scale (SF-36 BPS), and Measure of Intermittent and Constant Osteoarthritis Pain (ICOAP). Arthritis care \& research, 63 Suppl 11, S240-S252.

Karandikar, N., \& Vargas, O. O. (2011). Kinetic chains: a review of the concept and its clinical applications. $P M \& R$ : the journal of injury, function, and rehabilitation, 3(8), 739-745.

Khan, M., Pretty, C. G., Amies, A. C., Balmer, J., Banna, H. E., Shaw, G. M., \& Geoffrey Chase, J. (2017). Proof of concept noninvasive estimation of peripheral venous oxygen saturation. Biomedical engineering online, 16(1), 60.

Kocjan, J., Adamek, M., Gzik-Zroska, B., Czyżewski, D., \& Rydel, M. (2017). Network of breathing. Multifunctional role of the diaphragm: a review. Advances in respiratory medicine, 85(4), 224-232.

Koçyiğit H, Aydemir Ö, Ölmez N, et al. (1999). Reliability and validity of the SF-36 for Turkish. Journal of Medicine and Treatment. 1999;12:102- 6.

Kurşun, Y. Z., Yıldız, F., Kaymaz, Ö., \& Önal, S. A. (2015). Ağrılı kanser hastalarının tedavisinde analjezik basamak tedavisinin yeri [Analgesic step ladder treatment in cancer patients with pain]. Agri: Agri (Algoloji) Dernegi'nin Yayin organidir = The journal of the Turkish Society of Algology, 27(1), 26-34.

Kuzu M, Taş O, Tulum G. (2017). Remote Monitoring Patient Parameters System. 2nd National Biomedical Device Design and Production Symposium May 16, 2017.

Langhorne, P., Stott, D. J., Robertson, L., MacDonald, J., Jones, L., McAlpine, C., Dick, F., Taylor, G. S., \& Murray, G. (2000). Medical complications after stroke: a multicenter study. Stroke, 31(6), 1223-1229.

Lee B. K. (2015). Effects of the combined PNF and deep breathing exercises on the ROM and the VAS score of a frozen shoulder patient: Single case study. Journal of exercise rehabilitation, 11(5), 276-281.

Magee DJ (2008). Orthopedic Physical Assessment. 5 th ed. St. Louis, MO: Saunders Elsevier.

Murray, C. J., Atkinson, C., Bhalla, K., Birbeck, G., Burstein, R., Chou, D., Dellavalle, R.,
Danaei, G., Ezzati, M., Fahimi, A., Flaxman, D., Foreman, Gabriel, S., Gakidou, E., Kassebaum, N., Khatibzadeh, S., Lim, S., Lipshultz, S. E., London, S., Lopez, ... U.S. Burden of Disease Collaborators (2013). The state of US health, 1990-2010: burden of diseases, injuries, and risk factors. JAMA, 310(6), 591-608.

Neviaser, A. S., \& Hannafin, J. A. (2010). Adhesive capsulitis: a review of current treatment. The American journal of sports medicine, 38(11), 2346-2356.

Nobre e Souza, M. Â., Lima, M. J., Martins, G. B., Nobre, R. A., Souza, M. H., de Oliveira, R. B., \& dos Santos, A. A. (2013). Inspiratory muscle training improves antireflux barrier in GERD patients. American journal of physiology. Gastrointestinal and liver physiology, 305(11), G862-G867.

Oliveira, F., de Fontenay, B. P., Bouyer, L. J., Desmeules, F., \& Roy, J. S. (2017). Effects of kinesiotaping added to a rehabilitation programme for patients with rotator cuff tendinopathy: protocol for a single-blind, randomised controlled trial addressing symptoms, functional limitations and underlying deficits. BMJ open, 7(9), e017951.

Osborne, J. D., Gowda, A. L., Wiater, B., \& Wiater, J. M. (2016). Rotator cuff rehabilitation: current theories and practice. The Physician and sportsmedicine, 44(1), 85-92.

Ryan, V., Brown, H., Minns Lowe, C. J., \& Lewis, J. S. (2016). The pathophysiology associated with primary (idiopathic) frozen shoulder: A systematic review. BMC musculoskeletal disorders, 17(1), 340.

Schaffer, S. D., \& Yucha, C. B. (2004). Relaxation $\&$ pain management: the relaxation response can play a role in managing chronic and acute pain. The American journal of nursing, 104(8), 75-82.

Sciascia, A., \& Cromwell, R. (2012). Kinetic chain rehabilitation: a theoretical framework. Rehabilitation research and practice, 2012, 853037.

Sundstrup, E., \& Andersen, L. L. (2017). Hard Physical Work Intensifies the Occupational Consequence of Physician-Diagnosed Back Disorder: Prospective Cohort Study with Register Follow-Up among 10,000 
Workers. International journal of rheumatology, 2017, 1037051.

Stephens, R. J., Haas, M., Moore, W. L., 3rd, Emmil, J. R., Sipress, J. A., \& Williams, A. (2017). Effects of Diaphragmatic Breathing Patterns on Balance: A Preliminary Clinical Trial. Journal of manipulative and physiological therapeutics, 40(3), 169-175.

Struyf, F., Geraets, J., Noten, S., Meeus, M., \& Nijs, J. (2016). A Multivariable Prediction Model for the Chronification of Nontraumatic Shoulder Pain: A Systematic Review. Pain physician, 19(2), 1-10.

Jerath, R., Crawford, M. W., Barnes, V. A., \& Harden, K. (2015). Self-regulation of breathing as a primary treatment for anxiety. Applied psychophysiology and biofeedback, 40(2), 107-115.

How to cite this article: Şahin, O. and Kocamaz, D. (2021). Effects of Diaphragmatic Mobilization and Diaphragmatic Breathing Exercises on Pain and Quality of Life in Individuals with Shoulder Pain: A Randomized Controlled Trial. Int J Disabil SportsHealth Sci;4(2):113123.https://doi.org/10.3343/ijdshs.976285 